\title{
Evaluation of vascular wall elasticity of human digital arteries using alternating current-signal photoplethysmography
}

This article was published in the following Dove Press journal:

Vascular Health and Risk Management

4 June 2013

Number of times this article has been viewed

\author{
Pichitra Uangpairoj \\ Masahiro Shibata \\ Department of Bioscience and \\ Engineering, Shibaura Institute \\ of Technology, Saitama, Japan
}

Correspondence: Masahiro Shibata Department of Bioscience and Engineering, College of Systems Engineering and Science, Shibaura Institute of Technology, 307 Fukasaku, Minuma-ku, Saitama 337-8570, Japan $\mathrm{Tel}+8 \mathrm{I} 487206016$ Fax +8I 48720601 I

Email shibatam@sic.shibaura-it.ac.jp
Purpose: A simple method of estimating arterial elasticity in the human finger using a volumeoscillometric technique with photoplethysmography was principally studied under the various effects of age, sex, and cold-stress stimulation for testing the capability of using this technique in arterial elasticity analysis.

Methods: Amplitude variations in the alternating current signal of the photoplethysmograph during a continuous change in transmural pressure were analyzed to obtain the blood pressure and the transmural pressure-relative volume difference relationship of the arteries. We first tested the effect of the occluding cuff size on the arterial elasticity analysis in eight subjects (ages 20-45 years) to obtain a suitable cuff size, resulting in the selection of a middle cuff with a $22 \mathrm{~mm}$ diameter. Blood pressure and arterial elasticity were measured in six groups of subjects separated into three age-groups of women and men (ages 20-25, 32-45, and over 50 years) for testing the effect of age and sex. Twelve subjects (ages 20-25 years) also had their blood pressure and arterial elasticity measured in three conditions under the influence of the cold-stress stimulation.

Results: Age, sex, and cold-stress stimulation had an impact on mean blood pressure $(P<0.0005,0.025)$, whereas pulse pressure and heart rate were statistically unchanged by those factors. Furthermore, an advanced age (over 50 years) was found to induce an increase in relative volume difference values $(P<0.025)$ and upward shifting of the transmural pressure-relative volume difference relationships, whereas sex, level of mean blood pressure, and cold-stress stimulation had no influence on these forms of the index.

Conclusion: This study showed the usefulness of the relative volume difference as being a mean blood pressure-independent indicator for changes in arterial elasticity.

Keywords: arterial elasticity, volume oscillometry, noninvasive technique, aging process, cold-stress stimulation

\section{Introduction}

Arteriosclerosis is a vascular disease caused by aging that can be seen throughout society. ${ }^{1}$ When arterial blood vessels are subjected to the continuous stress of blood flow for long time periods, the elastin fibers in the media layer of the arterial wall become injured and fragmented, resulting in the recruitment of collagen fibers. This structural change in the arterial wall causes a slackening that progresses to a reduction in wall elasticity. ${ }^{2}$ The stiffening of the arterial wall reduces the absorption and restoration capability of the vessels during systole and diastole, raising systolic blood pressure and pulse pressure. ${ }^{3}$ A reduction in arterial elasticity is also associated with the existence and development of other cardiovascular diseases., ${ }^{4,5}$ 
Several methods for measuring arterial stiffness have been developed over the last century. Pulse pressure has been widely used to define the influence of large artery stiffness. Pulse pressure explicitly increases with age, especially over the age of 60 years, ${ }^{6}$ and is associated with a dominant rise in arterial stiffening. However, pulsepressure amplification at the peripheral site may lead to misinterpretations of hypertension, particularly in young subjects. ${ }^{7}$ Thus, pulse pressure may not be an excellent marker for assessing arterial stiffness. Pulse-wave velocity (PWV) and augmentation index (AIx) are widely used as standard arterial stiffness predictors. Increases in PWV and AIx in the elderly reflect arterial stiffening due to the aging process. ${ }^{8-11}$ In addition, high PWV and AIx also relate to the morbidity and mortality of patients with associated cardiovascular diseases; for example, in patients with coronary heart disease, ${ }^{12}$ hypercholesterolemia, ${ }^{13}$ stroke, ${ }^{4}$ diabetes, glucose intolerance, ${ }^{14,15}$ end-stage renal failure, ${ }^{16}$ and spinal cord injury. ${ }^{17}$ Nonetheless, PWV depends on the mean blood pressure of subjects. ${ }^{10,18,19}$ Vasodilation and vasoconstriction due to sympathetic nervous stimulation, such as heat- and cold-stress stimulations, also obviously influence the AIx. ${ }^{20,21}$ Thus, using PWV and AIx for the arterial stiffness measurement under various conditions of mean blood pressure and vascular stimulations cannot definitely indicate the arterial stiffness, due to the structural peculiarities of the arterial wall. Furthermore, with advances in imaging technology, ultrasound and magnetic resonance imaging have been exploited to track the position of the arterial wall noninvasively. Various arterial stiffness indices can be calculated from these imaging techniques. However, these techniques are expensive to perform for daily health monitoring. In contrast, photoplethysmography (PPG) is another noninvasively optical technique that is simple, small, compact, and reasonable. PPG is broadly used in clinical monitoring, such as for cutaneous blood flow, ${ }^{22}$ blood oxygen saturation, heart rate, blood pressure, ${ }^{23,24}$ and vascular assessments, including arterial stiffness. ${ }^{25}$

The basic PPG system consists of essentially two components: an infrared light source and a photo sensor. The infrared light source generates infrared light that penetrates deeply to the target site, and is partly absorbed by the skin, tissue, bone, and blood, whereas the remaining light transmits and reflects outwards. A photo sensor is used to detect and change the remaining light to electric current before transforming it into the two components of the output signal through a filter process and signal amplification. These two signal components of PPG are a steady direct current signal (DC signal) and an alternating current signal (AC signal). The DC signal, which is associated with the lightabsorption ability of the venous blood, nonpulsatile arterial blood, and the surrounding tissues, represents the total blood volume, while the AC signal reflects the light absorption caused by pulsatile arterial blood variation during the cardiac cycle. ${ }^{22}$ Many researchers have utilized the components of the PPG signal for clinical monitoring, including arterial stiffness assessments. In 1986, Kawarada et al used the PPG to evaluate arterial elasticity in human fingers and rabbit forelegs. Their transmission-mode PPG system had an occluding cuff to induce vascular volume changes in arterial elasticity measurements using a volume-oscillometric method. The vascular elasticity markers - relative volume change and volume elastic modulus - were obtained from transmitted light intensity using the Lambert-Beer law. The relationship between transmural pressure and the vascular elasticity markers demonstrated the predictive value of PPG in arterial elasticity assessments performed under the influence of atheroma and a vasodilator. ${ }^{26}$ The relationship between relative volume change and transmural pressure was also associated with the effects of aging, hypertension, and coronary disease in a study by Ando et al. In their study, the relative volume change declined with age, hypertension, and coronary disease. ${ }^{27}$ Furthermore, the characteristics of the PPG pulse wave, including its derivative, were considered in the analysis of arterial stiffness using several parameters; for example, the arterial stiffness index, ${ }^{10,15} \mathrm{AIx},{ }^{28-30}$ and the $\mathrm{b} / \mathrm{a}, \mathrm{c} / \mathrm{a}, \mathrm{d} / \mathrm{a}$, and e/a ratios from the systolic and diastolic waves of the second derivative of the PPG pulse wave. ${ }^{30,31}$ Moreover, pulse-wave decomposition is another useful technique for obtaining indices of arterial stiffness. ${ }^{32}$ All the aforementioned parameters were demonstrated to be affected by age and were valid for analyses of arterial stiffness.

Although amplitude variations in the PPG pulse wave can express arterial elasticity in the form of the finger arterial elasticity index, and the normalized finger arterial stiffness index, ${ }^{33}$ PPG amplitude variations still have not prevailed for general measurements of arterial elasticity. Meanwhile, a few studies have focused on factors that affect arterial elasticity analysis using PPG amplitude variations. Therefore, in the present study, the significance of PPG amplitude variations was considered, and a simple alternative methodology for the quantification of arterial elasticity by analyzing amplitude variations in the PPG pulse wave in the human finger is proposed. We also applied this method for testing the capability of using PPG amplitude variations in arterial elasticity analysis under the influences of cuff size, age, sex, 
and cold-stress stimulation, which are basic factors in arterial elasticity measurements, excluding pathophysiological conditions.

\section{Methods}

\section{Measurements and instruments}

\section{Blood pressure and heart rate measurement}

Systolic blood pressure $\left(\mathrm{P}_{\text {sys }}\right)$, diastolic blood pressure $\left(\mathrm{P}_{\text {dia }}\right)$, and heart rate were measured using an automatic blood pressure monitor (HEM-7070; Omron, Dalian, People's Republic of China) positioned on the left brachium of subjects. The mean blood pressure $\left(\mathrm{P}_{\mathrm{m}}\right)$ of the brachial artery was calculated by summing $\mathrm{P}_{\text {dia }}$ and one-third of the pulse pressure $(\Delta \mathrm{P})$, which is the subtraction of the $\mathrm{P}_{\text {sys }}$ from the $\mathrm{P}_{\text {dia }}$.

\section{Skin-temperature measurement}

The skin temperature of subjects was measured using a noncontact thermometer (Thermo pipper; Sato Shouji, Kanagawa, Japan) placed $1 \mathrm{~cm}$ above the dorsal surface of the proximal phalanx of the index finger.

\section{Finger-diameter measurement}

The horizontal and vertical diameters of the right index finger were measured using a vernier caliper (series 503; Mitutoyo, Kawasaki, Japan) at the middle of the proximal phalanx of the right index finger.

\section{Arterial elasticity measurement}

In this study, the PPG signals of the human finger were measured using a developed optical plethysmograph device based on a commercial model (BP-98AL; Softron, Tokyo, Japan), as shown in Figure 1. A reflection-mode PPG has a light-emitting diode with a wavelength of $850 \mathrm{~nm}$ placed side-by-side with a photo sensor (wavelength 320-1100 nm) inside an occluding cuff. The device was positioned on the dorsal side of the proximal phalanx of the right index finger during the measurement. The PPG signal detected by the photo sensor was transformed and decomposed into $\mathrm{AC}$ and DC components of the electric current. The AC component was filtered using cutoff filters with a low frequency of $0.75 \mathrm{~Hz}$ (a second-order infinite impulse-response high-pass filter) and a high frequency of $10 \mathrm{~Hz}$ (100th-order finite impulse-response low-pass filter). Moreover, three sizes of occluding cuffs with inner diameters of $20 \mathrm{~mm}, 22 \mathrm{~mm}$, and $24 \mathrm{~mm}$ were used to generate extravascular pressure or cuff pressure $\left(\mathrm{P}_{c}\right)$ on the index finger. In this measurement, $\mathrm{P}_{\mathrm{c}}$ was gradually decreased from $180 \mathrm{mmHg}$ to $0 \mathrm{mmHg}$ with an approximate deflation rate of $4 \mathrm{mmHg} / \mathrm{s}$. The $\mathrm{AC}$, $\mathrm{DC}$, and $\mathrm{P}_{\mathrm{c}}$ signals were sampled at a rate of $1000 \mathrm{~Hz}$ per channel and were converted to digital outputs using a 24-bit A/D converter (PowerLab 4/26, ML846; ADInstruments, Dunedin, New Zealand) before storing them on a personal computer (Optiplex 980; Dell, Round Rock, TX, USA).

With this PPG measurement, the other tissues around the vascular system of the target site were assumed to be incompressible. The measurement started when both the venous and arterial systems were collapsed by the cuff pressure at $180 \mathrm{mmHg}$. During the deflation of the occluding cuff, the venous system was continuously collapsed, ${ }^{24}$ whereas the arterial blood system started to

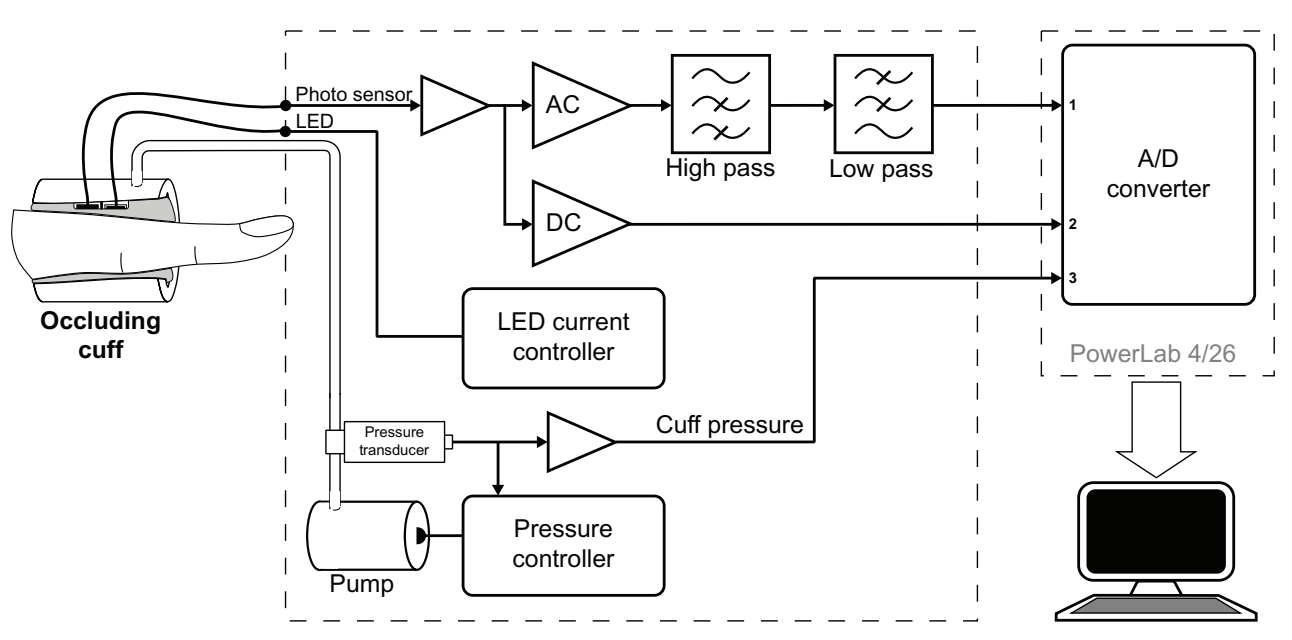

Figure I Schematic block diagram of a photoplethysmograph system for the human finger.

Notes: The light-emitting diode (LED) system generates an infrared light directed toward the finger. The pressure generator induces a vascular volume change through the occluding cuff. The photo sensor detects the reflected light from the finger. The electric current from the photo sensor is decomposed into an alternating current (AC) and a direct current (DC). The AC current is then filtered through a high-pass and a low-pass filter. The A/D converter converts the AC, DC, and cuff-pressure input signals to the digital outputs before storing them on the personal computer. 
flow when the $P_{c}$ was equal to the $P_{\text {sys }}$. At this stage, the fluctuation in the AC signal began to be recognizable, as shown in Figure 2. The fluctuation in the AC signal illustrated the existence of blood flow in the arterial system. The arterial volume change was controlled by the continuous change in the $\mathrm{P}_{c}$ and transmural pressure $\left(\mathrm{P}_{t r}\right)$, which corresponds to the difference between the $\mathrm{P}_{\mathrm{m}}$ and $\mathrm{P}_{\mathrm{c}}$, during the deflation. At the maximum amplitude of the AC signal, this point expressed the equality between the $\mathrm{P}_{c}$ and $\mathrm{P}_{\mathrm{m}}$. At this point, the $\mathrm{P}_{\text {tr }}$ was equal to zero. Therefore, the $\mathrm{P}_{\text {sys }}$ and $\mathrm{P}_{\mathrm{m}}$ were determined based on the correspondence between the AC and $\mathrm{P}_{c}$ signals. Furthermore, when the $\mathrm{P}_{\mathrm{c}}$ was equal to or less than the $\mathrm{P}_{\mathrm{m}}$, the $\mathrm{P}_{\text {tr }}$ was greater than zero, and the amplitude of the AC signal represented the arterial volume difference between systole and diastole $(\Delta \mathrm{V})$. Therefore, when the $\mathrm{P}_{\text {tr }}$ increased from zero, the variation in the AC amplitude indicated a change in the arterial elastic property. The relative volume difference was proposed as an index of arterial elasticity. The relative volume difference was defined as the volume difference at any $\mathrm{P}_{\text {tr }}(\Delta \mathrm{V})$ normalized with that for zero $\mathrm{P}_{\text {tr }}\left(\Delta \mathrm{V}_{0}\right)$ or $\Delta \mathrm{V} / \Delta \mathrm{V}_{0}$. This index was also derived from the light intensity of the AC signal as follows:

$$
\Delta \mathrm{V} / \Delta \mathrm{V}_{0}=\mathrm{I} / \mathrm{I}_{0}
$$

where $\mathrm{I}$ is the $\mathrm{AC}$ amplitude at any $\mathrm{P}_{\mathrm{tr}}$, in volts, and $\mathrm{I}_{0}$ is the AC amplitude at zero $P_{t r}$, in volts.

The stored output data from PPG was analyzed offline using MatLab (MathWorks, Natick, MA, USA) to extract the peaks and the amplitudes from the AC signal to determine the $\mathrm{P}_{\mathrm{m}}, \mathrm{P}_{\mathrm{tr}}, \Delta \mathrm{V}, \Delta \mathrm{V}_{0}$, and $\Delta \mathrm{V} / \Delta \mathrm{V}_{0}$. In the output signal analysis, we could extract the amplitudes of the AC signal from the maximum amplitude until the end of the constant amplitudes. Because we found that the amplitudes of the AC signal were influenced by the withdrawal of the $\mathrm{P}_{\mathrm{c}}$ from the finger during the last period of the occlusion, we did not therefore regard the signal during that period. The average minimum $\mathrm{P}_{c}$ that we took into account for the arterial elasticity analysis was approximated to be $28.5 \pm 7.7 \mathrm{mmHg}$, which was different among the groups of data. Furthermore, a signal-matching algorithm was also utilized to obtain the starting point of the AC signal when determining the $\mathrm{P}_{\text {sys }}$. Then, we calculated the $\mathrm{P}_{\text {dia }}$ and the $\Delta \mathrm{P}$ from the $\mathrm{P}_{\text {sys }}$ and $\mathrm{P}_{\mathrm{m}}$ as follows:

$$
\mathrm{P}_{\mathrm{dia}}=\left(3 \mathrm{P}_{\mathrm{m}}-\mathrm{P}_{\mathrm{sys}}\right) / 2
$$

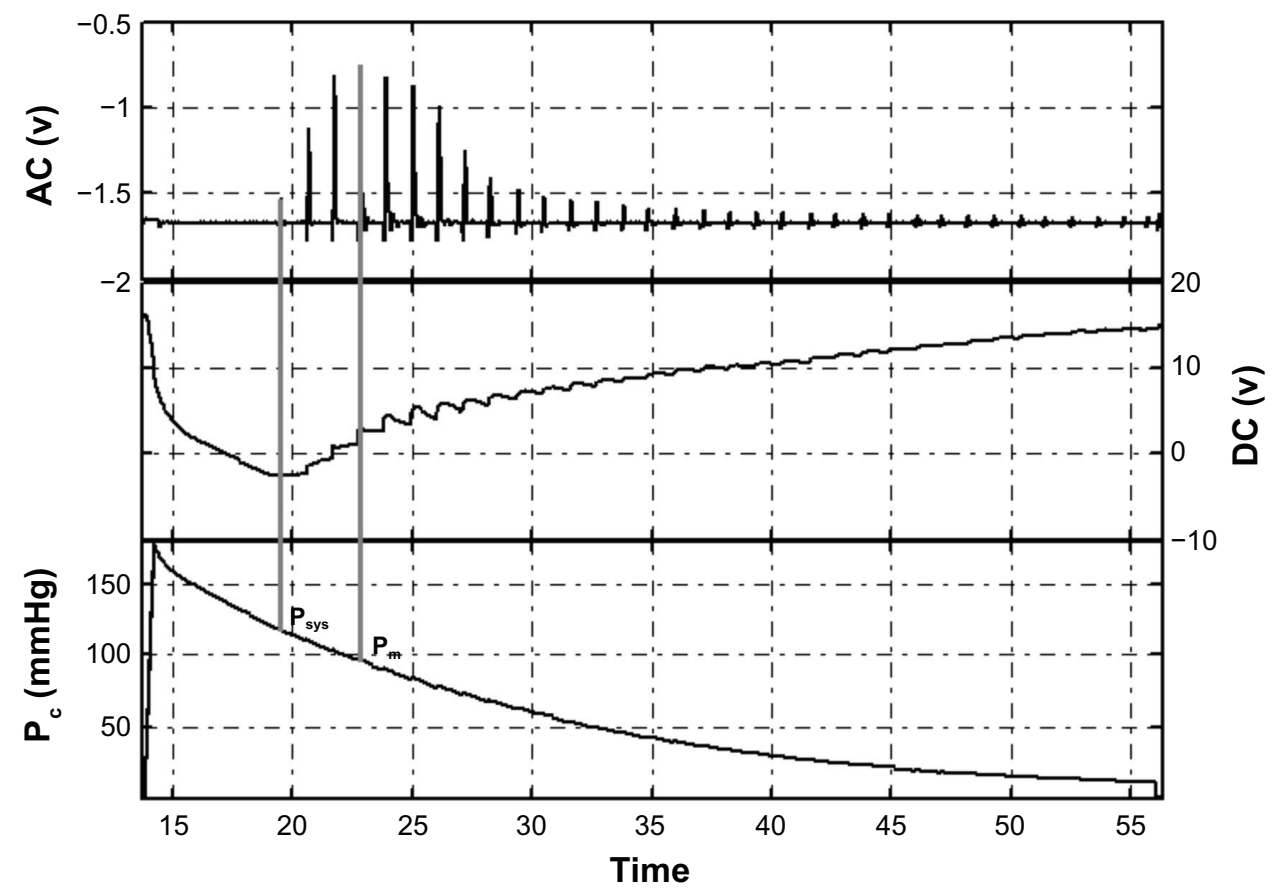

Figure 2 Example of the recorded output signals from the photoplethysmograph: the alternating current (AC), direct current (DC), and cuff-pressure ( $\left.\mathrm{P}_{c}\right)$ signals are shown.

Notes: The $P_{c}$ started to compress and collapse the arterial system at $180 \mathrm{mmHg}$. The $P_{c}$ gradually decreased because of the deflation of the occluding cuff. When the $P_{c}$ was equal to the systolic blood pressure $\left(P_{s y s}\right)$, the fluctuation in the $A C$ signal started to be recognized. When the $P_{c}$ was equal to the mean blood pressure $\left(P_{m}\right)$, the transmural pressure $\left(P_{t r}\right)$ was zero and the amplitude of the $A C$ signal reached its highest value. When the $P_{c}$ was equal to or less than $P_{m}$, the amplitude of the $A C$ signal implied the arterial volume difference between systole and diastole $(\Delta \mathrm{V})$. The relative volume difference $(\Delta \mathrm{V} / \Delta \mathrm{V} /)$ was derived from the light intensity of the $A C$ signal using the ratio of the $A C$ amplitude at any $P_{\text {tr }}$ to the $A C$ amplitude at zero $P_{\text {tr }}$. 


$$
\Delta \mathrm{P}=\mathrm{P}_{\text {sys }}-\mathrm{P}_{\text {dia }}
$$

Based on the PPG signal analysis performed using MatLab, the arterial elasticity of subjects was expressed as the relationship between $\mathrm{P}_{\text {tr }}$ and $\Delta \mathrm{V} / \Delta \mathrm{V}_{0}$. The $\Delta \mathrm{V} / \Delta \mathrm{V}_{0}$ values at a $\mathrm{P}_{\mathrm{tr}}$ of $30 \mathrm{mmHg}$ obtained from the linear interpolation of the two nearest data points were used for comparing the $\Delta \mathrm{V} / \Delta \mathrm{V}_{0}$ index at the specific $\mathrm{P}_{\text {tr }}$ among the groups of subjects.

\section{Subjects and experiment}

\section{Subjects}

In this study, 58 healthy subjects -28 women $20-63$ years old and 30 men 20-69 years old - participated in the experiments. The experimental protocol was approved by the ethics committee of the Shibaura Institute of Technology. The subjects were individually informed of the purposes and procedures of the experiments, and they also agreed in the informed consent before starting the measurements.

\section{Effect of occluding cuff size on arterial elasticity analysis}

The effect of the occluding cuff size on the arterial elasticity analysis was conducted using three cuff sizes (inner diameters of $20 \mathrm{~mm}, 22 \mathrm{~mm}$, and $24 \mathrm{~mm}$ ) in eight subjects (three women and five men, 20-45 years old) to determine the most suitable cuff size for the subsequent analyses. We performed the measurements in a quiet room at a temperature of $24^{\circ} \mathrm{C} \pm 1^{\circ} \mathrm{C}$. After the subjects had rested in a sitting position for 10 minutes, their $\mathrm{P}_{\text {sys }}, \mathrm{P}_{\text {dia }}$, and heart rate were measured at the left brachium. Next, the skin temperature and finger diameter of the right index finger were measured before applying the PPG cuff on the finger. Afterward, PPG measurement was performed by recording the PPG signals from the right index finger positioned at the same level as the heart.

\section{Effects of age and sex on arterial elasticity analysis}

After an acceptable cuff size was acquired, the arterial elasticity analysis of the amplitude variation in the AC signal of the PPG was performed in six groups of subjects - eight women and eight men, 20-25 years old; five women and five men, 32-45 years old; and six women and six men, over 50 years old - at a room temperature of $24^{\circ} \mathrm{C} \pm 1{ }^{\circ} \mathrm{C}$. The subjects started the experiment by resting in a sitting position for 10 minutes. After that, blood pressure, heart rate, and skin temperature were measured at the left brachium and the right index finger. Finally, PPG measurement was conducted by recording the PPG signals from the right index finger positioned at the same level as the heart.

\section{Effect of cold-stress stimulation on arterial elasticity analysis}

The effect of cold-stress stimulation on the arterial elasticity analysis was investigated in six women and six men, 20-25 years old. We also conducted this experiment in a quiet room at a temperature of $24^{\circ} \mathrm{C} \pm 1{ }^{\circ} \mathrm{C}$. In pre-coldstress stimulation, the subjects had rested in a sitting position for 10 minutes, then their blood pressure and heart rate were measured at the left brachium. The skin-temperature measurement was performed at the right index finger. The PPG signals were subsequently recorded from the right index finger. Afterward, the subjects proceeded to the cold-stress stimulation by immersing their left hands into $5^{\circ} \mathrm{C} \pm 1{ }^{\circ} \mathrm{C}$ water positioned at the same level as the heart for 4 minutes. The blood pressure and the PPG measurements were continued at the left brachium and the right index finger, respectively, after starting cold-stress stimulation for 1 minute. After finishing the cold-stress stimulation, the subjects proceeded to post-cold-stress stimulation by repeating the procedures conducted before the cold-stress stimulation.

\section{Statistical analysis}

The $\mathrm{P}_{\mathrm{m}}, \Delta \mathrm{P}$, heart rate, and $\Delta \mathrm{V} / \Delta \mathrm{V}_{0}$ values were expressed as mean values and standard deviation. The relationships between the $\mathrm{P}_{\text {tr }}$ and the $\Delta \mathrm{V} / \Delta \mathrm{V}_{0}$ of each group were illustrated as average curves. We used Student's $t$-test to identify differences in $\mathrm{P}_{\mathrm{m}}$ and $\Delta \mathrm{P}$ between two locations: the brachium and the index finger. A two-way analysis of variance (ANOVA) was used to test differences in $\mathrm{P}_{\mathrm{m}}, \Delta \mathrm{P}$, heart rate, and $\Delta \mathrm{V} / \Delta \mathrm{V}_{0}$ among the six groups of subjects according to the effects of age and sex. In the study of the effects of age and sex on arterial elasticity, we tested two hypotheses with critical $P$-values of 0.05 and 0.001 . To control the familywise error rate of testing each hypothesis, we utilized the Bonferroni correction, ${ }^{34}$ and the critical $P$-values of 0.05 and 0.001 were consequently adjusted to be 0.025 and 0.0005 , respectively. One-way ANOVA was also used to estimate differences in $\mathrm{P}_{\mathrm{m}}, \Delta \mathrm{P}$, heart rate, and $\Delta \mathrm{V} / \Delta \mathrm{V}_{0}$ among the three conditions according to the influence of the cold-stress stimulation. We also determined mean differences in the average finger diameter, $\mathrm{P}_{\mathrm{m}}$, and $\Delta \mathrm{V} / \Delta \mathrm{V}_{0}$ between two groups of data using Student's $t$-test. The correlations of $\mathrm{P}_{\mathrm{m}}$ against age, and the $\Delta \mathrm{V} / \Delta \mathrm{V}_{0}$ value at a $\mathrm{P}_{\text {tr }}$ of $30 \mathrm{mmHg}$ against age were modeled using a linear regression. 


\section{Results}

\section{Effect of occluding cuff size on arterial elasticity analysis}

To examine the effect of occluding cuff size on arterial elasticity measurements, subjects were separated into two groups according to average finger diameter. In the first group, five subjects had a moderate index finger size, with an average diameter of $16.9 \pm 0.5 \mathrm{~mm}$. Meanwhile, in the other group, three subjects had an average index finger diameter of $18.8 \pm 0.3 \mathrm{~mm}$, which was significantly larger than that of the first group $(P<0.001)$. When the PPG measurements were performed using three cuff sizes $(20 \mathrm{~mm}, 22 \mathrm{~mm}$, and $24 \mathrm{~mm}$ in inner diameter), the relationships between $\mathrm{P}_{\mathrm{tr}}$ and $\Delta \mathrm{V} / \Delta \mathrm{V}_{0}$ were clearly dissimilar between the two groups. Figure 3 shows the $\mathrm{P}_{\mathrm{tr}}-\Delta \mathrm{V} / \Delta \mathrm{V}_{0}$ relationships for the three cuff sizes in the moderate-finger subjects. The mean $\Delta \mathrm{V} / \Delta \mathrm{V}_{0}$ produced by the different cuff sizes decreased at much the same rate over the range of $\mathrm{P}_{\text {tr }}$. On the other hand, the cuff size apparently affected the $\mathrm{P}_{\mathrm{tr}}-\Delta \mathrm{V} / \Delta \mathrm{V}_{0}$ relationships in the large-finger subjects, as shown in Figure 4. Although mean $\Delta \mathrm{V} / \Delta \mathrm{V}_{0}$ decreased with $\mathrm{P}_{\mathrm{tr}}$ and no significant difference in mean $\Delta \mathrm{V} / \Delta \mathrm{V}_{0}$ was observed at any $\mathrm{P}_{\mathrm{tr}}$ for all three cuffs, the $\mathrm{P}_{\mathrm{tr}}-\Delta \mathrm{V} / \Delta \mathrm{V}_{0}$ curve for the $20 \mathrm{~mm}$ diameter cuff was shifted distinctly upwards, compared with the curves for both the $22 \mathrm{~mm}$ and $24 \mathrm{~mm}$ diameter cuffs. Furthermore, using the same occluding cuff size, the $\mathrm{P}_{\mathrm{tr}}-\Delta \mathrm{V} / \Delta \mathrm{V}_{0}$ relationship for the moderate-finger subjects significantly differed from that of the large-finger subjects $(P<0.05)$ when the $20 \mathrm{~mm}$ diameter cuff size was used, whereas the finger size of subjects did not significantly affect the $\mathrm{P}_{\mathrm{tr}}-\Delta \mathrm{V} / \Delta \mathrm{V}_{0}$ relationship obtained using the $22 \mathrm{~mm}$ and $24 \mathrm{~mm}$ diameter cuffs. Therefore, to avoid possible errors arising from the effect of

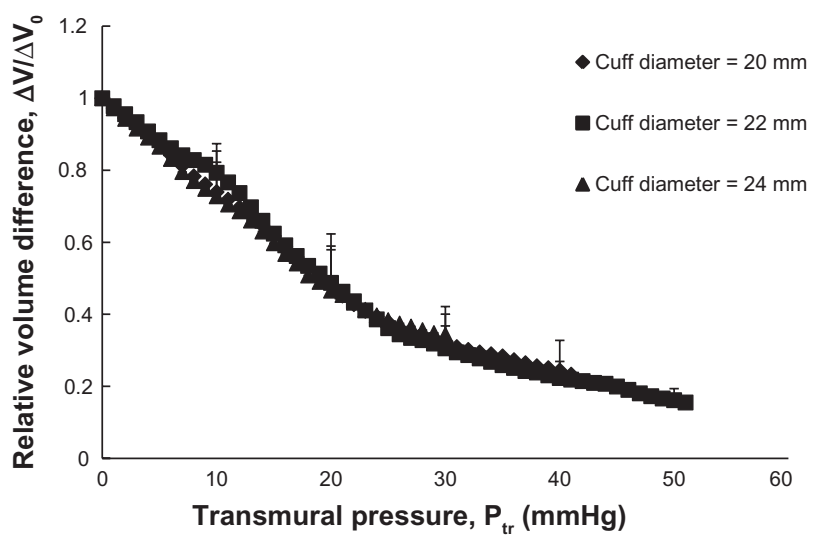

Figure 3 Relationships between the transmural pressure $\left(P_{t r}\right)$ and the relative volume difference $\left(\Delta \mathrm{V} / \Delta \mathrm{V}_{0}\right)$ in subjects with moderately sized fingers according to the occluding cuff size: $20 \mathrm{~mm}(\bullet), 22 \mathrm{~mm}(\boldsymbol{\bullet})$, and $24 \mathrm{~mm}(\Delta)$ diameter cuffs. Notes: $\Delta \mathrm{V} / \Delta \mathrm{V}_{0}$ is shown as the mean \pm standard deviation $(\mathrm{n}=5)$. The $\Delta \mathrm{V} / \Delta \mathrm{V}_{0}$ decreased with $P_{t r}$. There was no significant differences among the $P_{t r}-\Delta V / \Delta V_{0}$ curves obtained from the three cuff sizes.

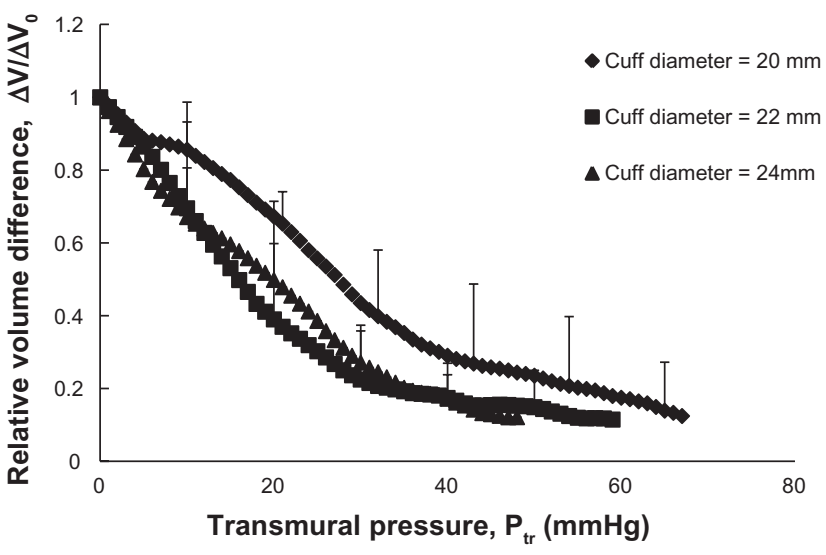

Figure 4 Relationships between the transmural pressure $\left(P_{t r}\right)$ and the relative volume difference $\left(\Delta \mathrm{V} / \Delta \mathrm{V}_{0}\right)$ in subjects with large fingers according to the occluding cuff size: $20 \mathrm{~mm}(\bullet), 22 \mathrm{~mm}(\boldsymbol{\nabla})$ and $24 \mathrm{~mm}(\boldsymbol{\Delta})$ diameter cuffs.

Notes: $\Delta \mathrm{V} / \Delta \mathrm{V}_{0}$ is shown as the mean \pm standard deviation $(\mathrm{n}=3)$. The $\Delta \mathrm{V} / \Delta \mathrm{V}_{0}$ decreased with the transmural pressure. The curves for the $20 \mathrm{~mm}$ diameter cuff differed from the curves for the 22 and $24 \mathrm{~mm}$ diameter cuffs. The small cuff with the $20 \mathrm{~mm}$ diameter seemed to affect the $\mathrm{P}_{\mathrm{tr}}-\Delta \mathrm{V} / \Delta \mathrm{V}_{0}$ relationship in subjects with large fingers.

the PPG cuff size, the medium cuff with a $22 \mathrm{~mm}$ diameter was used in subsequent arterial elasticity analyses.

\section{Effects of age and sex on arterial elasticity analysis \\ Blood pressure of subjects}

The average $\mathrm{P}_{\mathrm{m}}$ of the six groups of subjects (eight women and eight men, 20-25 years old; five women and five men, 32-45 years old; and six women and six men, over 50 years old) obtained from the left brachium and the right index finger are presented in Figure 5A. The $\mathrm{P}_{\mathrm{m}}$ of the brachial artery was significantly greater than that of the digital artery in almost every group of subjects $(P<0.0005,0.025)$ except for the 32- to 45-year-old men. However, the variations in the $\mathrm{P}_{\mathrm{m}}$ among the different groups of subjects were similar at the brachium and the index finger. Using two-way ANOVA, the age and sex of the subjects were shown to have a significant impact on the differences in the $\mathrm{P}_{\mathrm{m}}$ of brachial artery (age factor, $P<0.025$; sex factor, $P<0.0005$; and interaction, $P<0.0005$ ), as in Figure 5C, and digital artery (age factor, $P<0.025$; sex factor, $P<0.025$; and interaction, $P>0.025$ ), as in Figure 5D. In the digital artery, a comparison of the $\mathrm{P}_{\mathrm{m}}$ values among the groups of women showed that women over 50 years of age had a significantly higher $\mathrm{P}_{\mathrm{m}}$ than younger women $(P<0.0005)$. At the same time, 32- to 45-yearold women also had a significantly higher $\mathrm{P}_{\mathrm{m}}$ than 20- to 25 -year-old women $(P<0.025)$. In contrast, no significant differences in $\mathrm{P}_{\mathrm{m}}$ were observed among the three age-groups of men. Within the same range of age, the $\mathrm{P}_{\mathrm{m}}$ of the 20- to 25 -year-old men was significantly larger than that of the 20 - to 

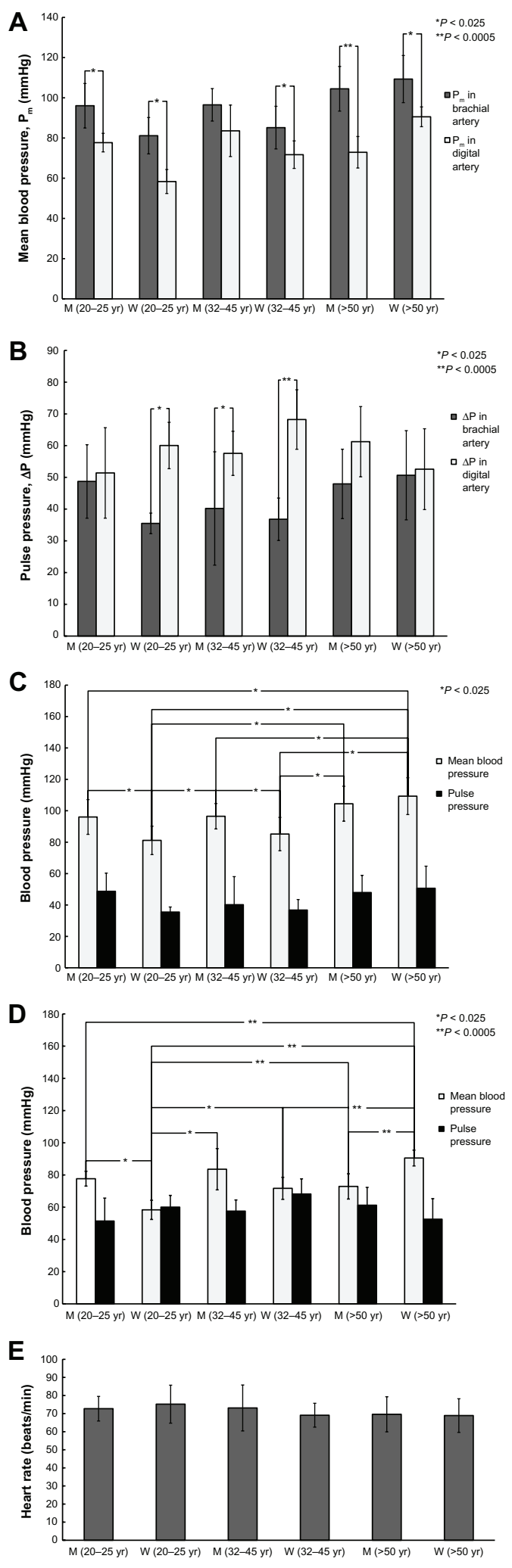

Figure 5 Average mean blood pressure $\left(\mathrm{P}_{\mathrm{m}}\right)$, pulse pressure $(\Delta \mathrm{P})$, and heart rate in six groups of subjects (eight women and eight men, 20-25 years old; five women and five men, 32-45 years old; and six women and six men, over 50 years old) presented in five subfigures: (A) average $P_{m}$ in the brachial (filled bars), and digital (open bars) arteries; (B) average $\Delta \mathrm{P}$ in the brachial (filled bars), and digital (open bars) arteries; (C) average $\mathrm{P}_{\mathrm{m}}$ (open bars), and $\Delta \mathrm{P}$ (filled bars) in the brachial artery; (D) average $\mathrm{P}_{\mathrm{m}}$ (open bars), and $\triangle \mathrm{P}$ (filled bars) in the digital artery; and $(\mathrm{E})$ average heart rate (filled bars).

Notes: $* P<0.025 ; * * P<0.0005$

Abbreviations: $M$, men; $W$, women. 25-year-old women $(P<0.025)$, while the men over 50 years old had a significantly lower $\mathrm{P}_{\mathrm{m}}$ than the women over 50 years old $(P<0.0005)$. However, no difference in $P_{\mathrm{m}}$ between sexes was seen in the 32- to 45 -year-old subjects. Furthermore, the overall relation between $P_{m}$ and age in Figure 6 expressed a positive correlation $\left(R^{2}=0.1179, P<0.025\right)$, which inferred a rise in $\mathrm{P}_{\mathrm{m}}$ with advancing age.

Figure $5 \mathrm{~B}$ shows the average $\Delta \mathrm{P}$ of the brachial and digital arteries. The $\Delta \mathrm{P}$ of the brachial artery was significantly lower than that of the digital artery in the 20- to 25 -yearold women and the 32- to 45-year-old men and women $(P<0.0005,0.025)$. Nonetheless, the age and sex of the subjects had no significant influence on differences in $\triangle \mathrm{P}$ among the groups for either the brachium (age factor, $P>0.025$; sex factor, $P>0.025$; and interaction, $P>0.025$ ), as in Figure 5C, or the index finger (age factor, $P>0.025$; sex factor, $P>0.025$; and interaction, $P>0.025$ ), as in Figure 5D. Moreover, Figure $5 \mathrm{E}$ shows no significant differences in heart rate among the six groups of subjects (age factor, $P>0.025$; sex factor, $P>0.025$; interaction, $P>0.025$ ).

\section{Effects of age and sex on the relationship between} transmural pressure and relative volume difference Based on the amplitude variation in the AC signal for the PPG measurement of the human index finger, the arterial elasticity of the six groups of subjects was analyzed and expressed as the average $\mathrm{P}_{\mathrm{tr}}-\Delta \mathrm{V} / \Delta \mathrm{V}_{0}$ relationship in Figure 7. Although mean $\Delta \mathrm{V} / \Delta \mathrm{V}_{0}$ decreased with $\mathrm{P}_{\mathrm{tr}}$ nonlinearly in all the groups of subjects, mean $\Delta \mathrm{V} / \Delta \mathrm{V}_{0}$ of the 20 - to 25 -yearold and the 32- to 45-year-old subjects decreased relative to the $\mathrm{P}_{\text {tr }}$ at a higher rate, compared with that in subjects over 50 years old. Therefore, the $\mathrm{P}_{\mathrm{tr}}-\Delta \mathrm{V} / \Delta \mathrm{V}_{0}$ curves for subjects over 50 years old were shifted upwards from the curves of the 20- to 25-year-old and the 32- to 45-year-old subjects.

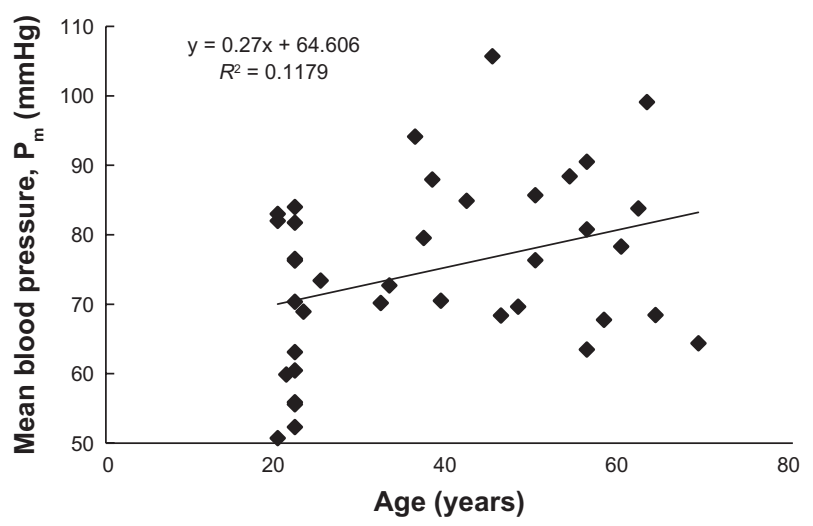

Figure 6 Positive correlation between mean blood pressure $\left(P_{m}\right)$ and age. Notes: $P_{m}$ tended to increase with advancing age. The correlation coefficient of the regression model was $0.27\left(R^{2}=0.1179, P<0.025, \mathrm{n}=38\right)$. 


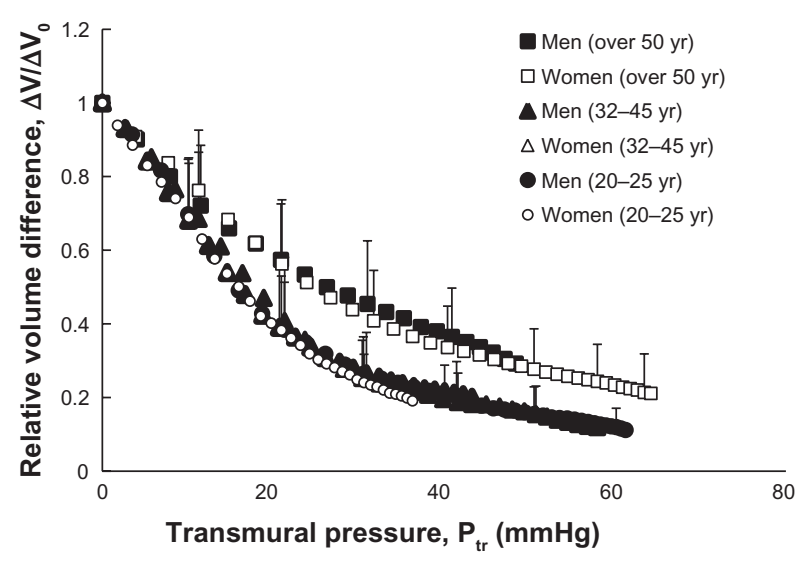

Figure 7 Relationships between transmural pressure $\left(P_{t r}\right)$ and relative volume difference $\left(\Delta \mathrm{V} / \Delta \mathrm{V}_{0}\right)$ in arterial elasticity analyses performed in six groups of subjects: eight women $(\circ)$ and eight men $(\bullet), 20-25$ years old; five women $(\Delta)$ and five men $(\Delta), 32-45$ years old; and six women $(\square)$ and six men ( $\square$ ), over 50 years old. Notes: The mean \pm standard deviation of $\Delta \mathrm{V} / \Delta \mathrm{V}_{0}$ in each group was plotted against the individual mean of $\mathrm{P}_{\mathrm{tr}}$. The $\mathrm{P}_{\mathrm{tr}}-\Delta \mathrm{V} / \Delta \mathrm{V}_{0}$ curves for the over 50 -year-old subjects obviously differed from the curves of the younger subjects. Sex had no impact on the difference among the $\mathrm{P}_{\mathrm{tr}}-\Delta \mathrm{V} / \Delta \mathrm{V}_{0}$ curves.

However, no difference in $\Delta \mathrm{V} / \Delta \mathrm{V}_{0}$ variation at any $\mathrm{P}_{\text {tr }}$ was seen between 20- to 25-year-old and 32- to 45-year-old subjects. Within the same range of age, difference in sex had no impact on $\Delta \mathrm{V} / \Delta \mathrm{V}_{0}$ variation over the range of $\mathrm{P}_{\text {tr }}$. Figure 8 shows mean $\Delta \mathrm{V} / \Delta \mathrm{V}_{0}$ values at a $\mathrm{P}_{\text {tr }}$ of $30 \mathrm{mmHg}$ in all the groups, corresponding to the $\mathrm{P}_{\mathrm{tr}}-\Delta \mathrm{V} / \Delta \mathrm{V}_{0}$ relationships. At a $\mathrm{P}_{\text {tr }}$ of $30 \mathrm{mmHg}$, mean $\Delta \mathrm{V} / \Delta \mathrm{V}_{0}$ values of the subjects over 50 years old were significantly larger than those of 20to 25-year-old and 32- to 45-year-old subjects $(P<0.025)$. Meanwhile, the mean $\Delta \mathrm{V} / \Delta \mathrm{V}_{0}$ values of 20- to 25-year-old subjects did not significantly differ from those of 32- to 45-year-old subjects. Two-way ANOVA showed a significant influence of age on differences in the mean $\Delta \mathrm{V} / \Delta \mathrm{V}_{0}$ values, while difference in sex had no impact on mean $\Delta \mathrm{V} / \Delta \mathrm{V}_{0}$ values (age factor, $P<0.0005$; sex factor, $P>0.025$; and interaction, $P>0.025)$. In addition, results of the linear regression between $\Delta \mathrm{V} / \Delta \mathrm{V}_{0}$ value at a $\mathrm{P}_{\text {tr }}$ of $30 \mathrm{mmHg}$ and age $\left(R^{2}=0.2891, P<0.0005\right)$ obtained in the 38 subjects indicated an increase in the $\Delta \mathrm{V} / \Delta \mathrm{V}_{0}$ value with age, as shown in Figure 9.

\section{Effect of cold-stress stimulation on arterial elasticity analysis}

\section{Effect of cold-stress stimulation on blood pressure}

Average $\mathrm{P}_{\mathrm{m}}, \Delta \mathrm{P}$, and heart rate of the brachial and digital arteries of twelve subjects obtained from three conditions - pre-cold-stress, cold-stress, and post-cold-stress stimulations - are shown in Figure 10. One-way ANOVA showed significant differences in $\mathrm{P}_{\mathrm{m}}$ among the three conditions $(P<0.05)$. While the $\mathrm{P}_{\mathrm{m}}$ of the brachial artery was significantly greater than that of the digital artery for the pre-cold-stress $(P<0.05)$ and post-cold-stress stimulations $(P<0.05)$, there was no significant difference in $\mathrm{P}_{\mathrm{m}}$ between the brachial and digital arteries for the cold-stress stimulation, as in Figure 10A. In the meantime, the $\mathrm{P}_{\mathrm{m}}$ of both the brachial (Figure 10B) and digital arteries (Figure 10C) for the cold-stress stimulation were significantly higher than those for the pre-cold-stress and post-cold-stress

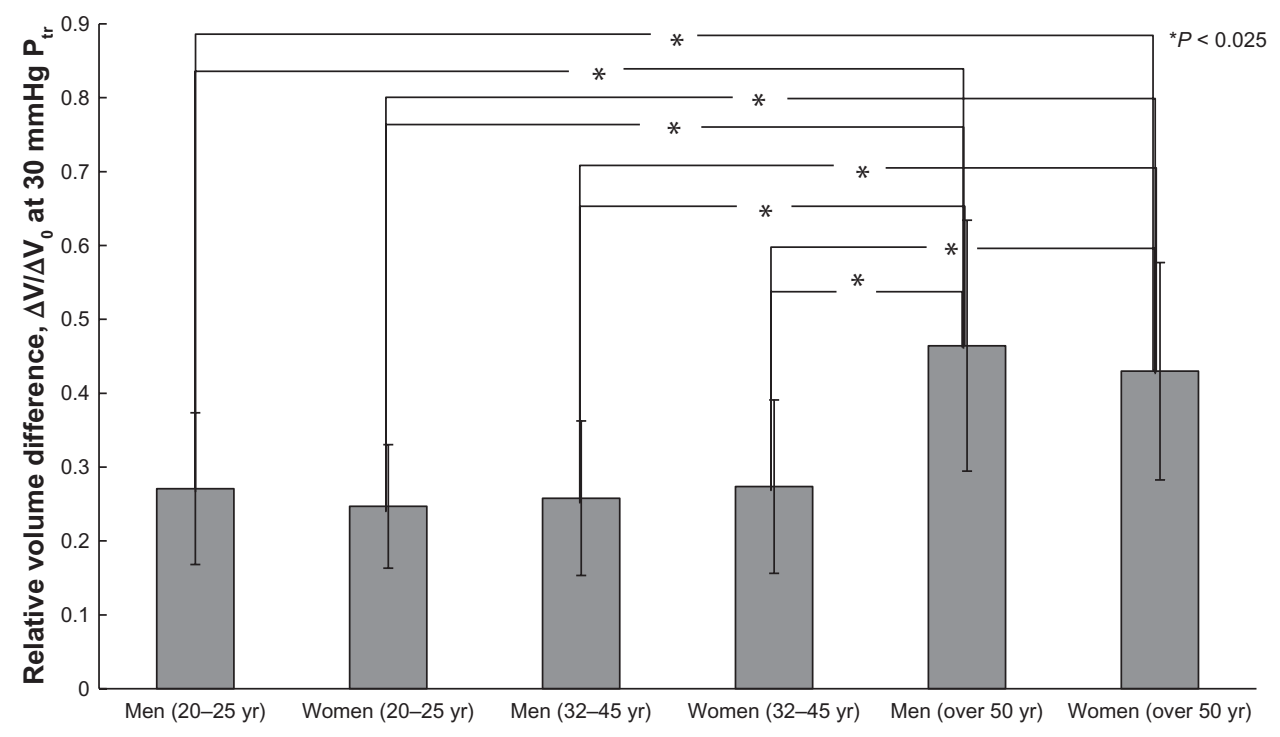

Figure 8 Relative volume differences $\left(\Delta \mathrm{V} / \Delta \mathrm{V}_{0}\right)$ at a transmural pressure $\left(\mathrm{P}_{\mathrm{tr}}\right)$ of $30 \mathrm{mmHg}$ in six groups of subjects: eight women and eight men, $20-25$ years old; five women and five men, 32-45 years old; and six women and six men, over 50 years old.

Notes: $\Delta \mathrm{V} / \Delta \mathrm{V}_{0}$ is shown as the mean \pm standard deviation. $\Delta \mathrm{V} / \Delta \mathrm{V}_{0}$ values of those over 50 years old were significantly greater than those of the younger subjects $(P<0.025)$, while sex had no impact on the difference in the mean $\Delta \mathrm{V} / \Delta \mathrm{V}_{0}$ values at a $\mathrm{P}_{\mathrm{tr}}$ of $30 \mathrm{mmHg}$. 


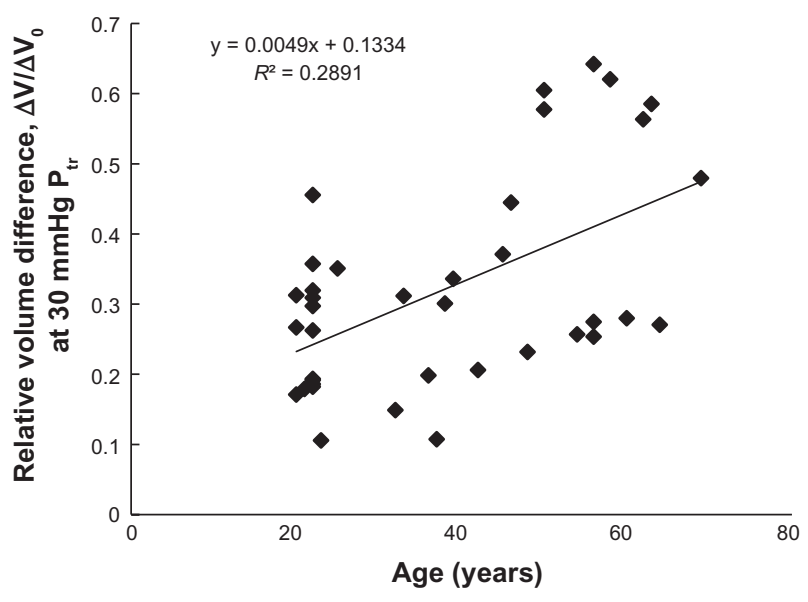

Figure 9 Positive correlation between the mean relative volume difference $\left(\Delta \mathrm{V} / \Delta \mathrm{V}_{0}\right)$ value at a transmural pressure $\left(\mathrm{P}_{\mathrm{tr}}\right)$ of $30 \mathrm{mmHg}$ and age.

Notes: Mean $\Delta \mathrm{V} / \Delta \mathrm{V}_{0}$ value at a $\mathrm{P}_{\mathrm{tr}}$ of $30 \mathrm{mmHg}$ tended to increase with advancing age. The correlation coefficient of the regression model was $0.0049\left(R^{2}=0.289\right.$, $\mathrm{P}<0.0005, \mathrm{n}=38)$.

stimulations $(P<0.05)$. The $\mathrm{P}_{\mathrm{m}}$ of both the brachial and digital arteries for the pre-cold-stress stimulation did not differ from those for the post-cold-stress stimulation. Figure 10B shows the $\Delta \mathrm{P}$ obtained from the brachial and digital arteries in the three conditions, and the $\Delta \mathrm{P}$ of the brachial artery was significantly lower than that of the digital artery for all the three conditions $(P<0.001)$. Nonetheless, using one-way ANOVA, no significant differences in $\Delta \mathrm{P}$ were observed for any of the three conditions in both the brachial $(P>0.05)$ and digital $(P>0.05)$ arteries. These results are illustrated in Figure 10C and D. Furthermore, there were no changes in heart rate for the three conditions $(P>0.05)$, as shown in Figure 10E.

\section{Effect of cold-stress stimulation}

\section{on relationship between transmural} pressure and relative volume difference

Average $\mathrm{P}_{\mathrm{tr}}-\Delta \mathrm{V} / \Delta \mathrm{V}_{0}$ relationships obtained from PPG measurement in twelve subjects for three conditions pre-cold-stress, cold-stress, and post-cold-stress stimulations - are illustrated in Figure 11. There were no significant differences in $\mathrm{P}_{\mathrm{tr}}-\Delta \mathrm{V} / \Delta \mathrm{V}_{0}$ relationships among the three conditions, and mean $\Delta \mathrm{V} / \Delta \mathrm{V}_{0}$ decreased at much the same rate over the range of $\mathrm{P}_{\text {tr }}$ for all three conditions. Moreover, there were no significant differences in mean $\Delta \mathrm{V} / \Delta \mathrm{V}_{0}$ values at a $\mathrm{P}_{\text {tr }}$ of $30 \mathrm{mmHg}$ among the three conditions: pre-cold-stress stimulation, $0.31 \pm 0.11$; cold-stress stimulation, $0.29 \pm 0.16$; and post-cold-stress stimulation, $0.31 \pm 0.10$; using one-way ANOVA $(P>0.05)$.
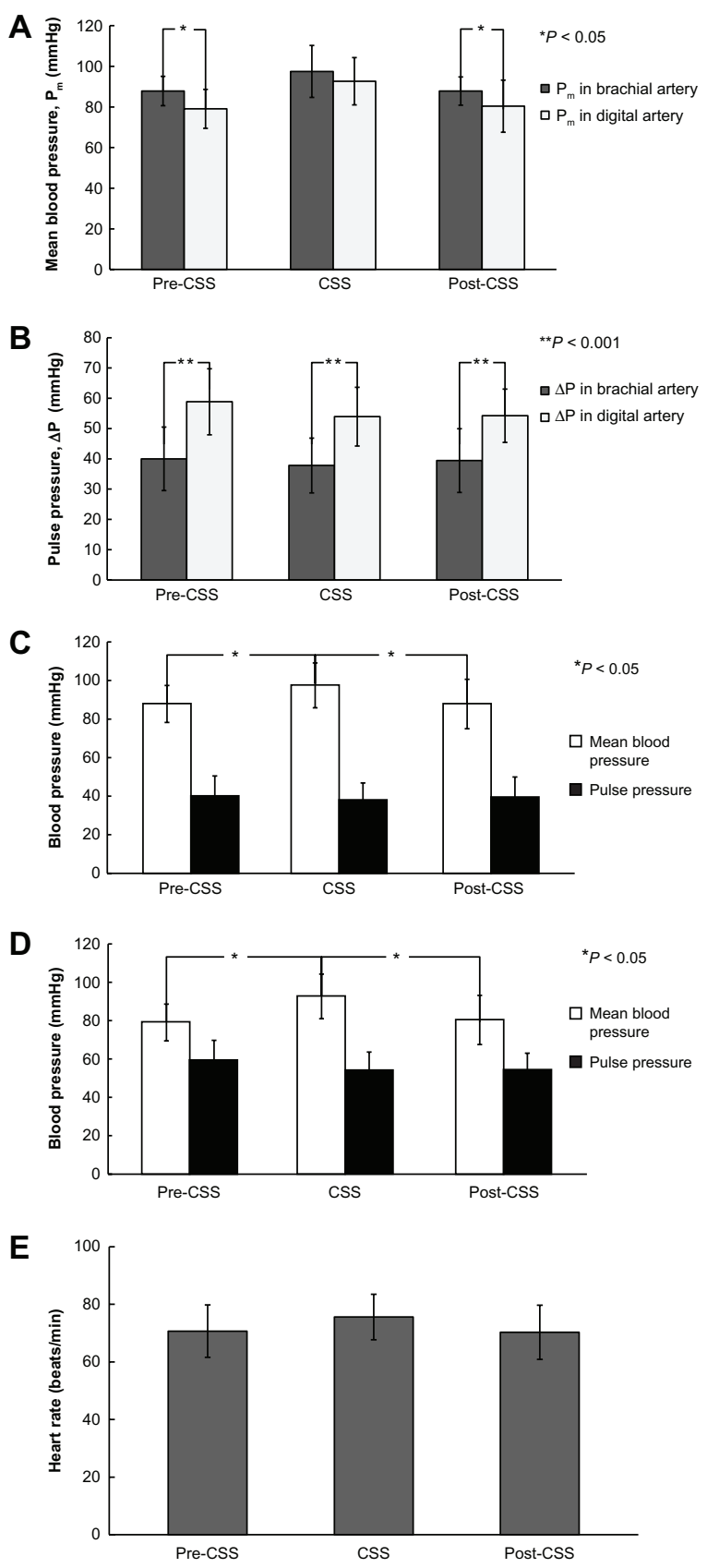

Figure 10 Average mean blood pressure $\left(P_{m}\right)$, pulse pressure $(\Delta P)$, and heart rate in twelve subjects according to the three conditions: pre-cold-stress stimulation (Pre-CSS), cold stress stimulation (CSS), and post-cold-stress stimulation (Post-CSS) presented in five subfigures: $(\mathbf{A})$ average $P_{m}$ in the brachial (filled bars), and digital (open bars) arteries; (B) average $\Delta \mathrm{P}$ in the brachial (filled bars), and digital (open bars) arteries; (C) average $P_{m}$ (open bars), and $\Delta P$ (filled bars) in the brachial artery; (D) average $P_{m}$ (open bars), and $\Delta P$ (filled bars) in the digital artery; and (E) average heart rate (filled bars).

Notes: $* P<0.05$; $* * p<0.001$.

\section{Discussion}

In the arterial elasticity analysis using variation in $\mathrm{AC}$ signal derived from PPG, no effect of the occluding cuff size was found in subjects with moderately sized fingers. However, the cuff size apparently impacted PPG measurements in 


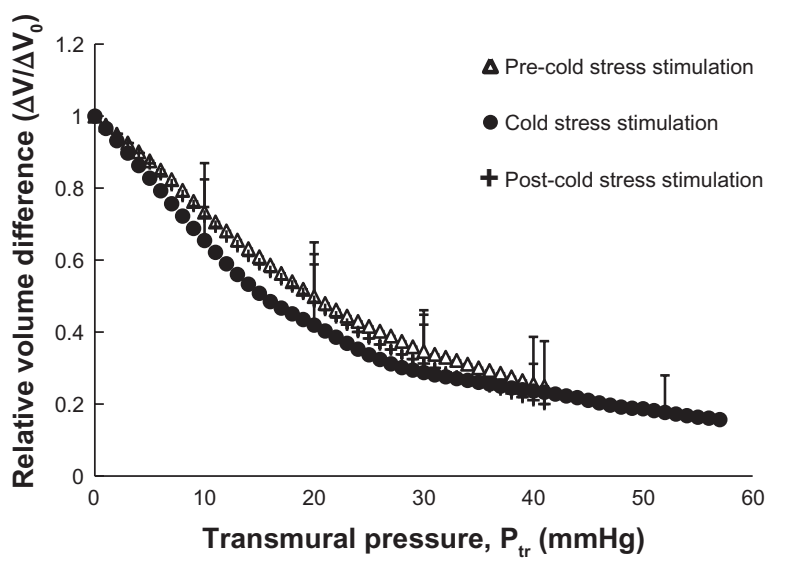

Figure I I Relationships between transmural pressure $\left(\mathrm{P}_{\mathrm{tr}}\right)$ and the relative volume difference $\left(\Delta \mathrm{V} / \Delta \mathrm{V}_{0}\right)$ according to the effect of cold-stress stimulation separated into three conditions: pre-cold-stress stimulation $(\Delta)$, cold-stress stimulation $(\bullet)$, and post-cold-stress stimulation (+).

Notes: The mean \pm standard deviation $(n=12)$ of the $\Delta V / \Delta V_{0}$ in each condition was plotted against the individual mean of the $P_{\text {tr }}$. There were no significant differences among the $\mathrm{P}_{\mathrm{tr}}-\Delta \mathrm{V} / \Delta \mathrm{V}_{0}$ curves obtained from all the three conditions.

subjects with large fingers by the upward shifting of the $\mathrm{P}_{\text {tr }}-\Delta \mathrm{V} / \Delta \mathrm{V}_{0}$ curve obtained using the $20 \mathrm{~mm}$ diameter cuff (which differed from the curves produced by the $22 \mathrm{~mm}$ and $24 \mathrm{~mm}$ diameter cuffs). Consequently, the vascular expansion of the digital artery was limited when the small cuff size was used. As a result, the $\Delta \mathrm{V} / \Delta \mathrm{V}_{0}$ value obtained using the small cuff was greater than that obtained using the larger cuffs at the same level of $\mathrm{P}_{t r}$. Thus, the excessively small cuff was not appropriate for arterial elasticity analyses using the AC signal of PPG. Meanwhile, Jones et al claimed that the oversize cuff was less accurate for assessments of PPG. ${ }^{35}$ Moreover, if the oversize cuff was loosely applied to a finger, the $\mathrm{P}_{c}$ could have been ineffectively transmitted to the finger, resulting in an overestimation of the mean blood pressure. Therefore, we decided to apply the medium cuff, with a $22 \mathrm{~mm}$ diameter, for the subsequent arterial elasticity analyses, even though the $22 \mathrm{~mm}$ and the $24 \mathrm{~mm}$ diameter cuffs statistically provided the same $\mathrm{P}_{\text {tr }}-\Delta \mathrm{V} / \Delta \mathrm{V}_{0}$ relationships for all finger sizes.

After the optimal cuff size was determined, this cuff size was used to measure blood pressure and arterial elasticity in six groups of subjects with a variety of ages and sexes. When mean blood pressures in the brachial and digital arteries of the subjects were examined, the $\mathrm{P}_{\mathrm{m}}$ in the digital artery was significantly lower than that in the brachial artery. The difference in the $\mathrm{P}_{\mathrm{m}}$ between these two locations was caused by an increase in vascular resistance of the small artery, leading to a pressure drop along the arterial tree. ${ }^{36}$ Nevertheless, the variations in the $\mathrm{P}_{\mathrm{m}}$ for both the brachial and the digital arteries were quite similar among the groups of subjects. These results affirmed the reliability and efficiency of using this PPG technique for measuring blood pressure, in agreement with the results for PPG measurements in normotensive and hypertensive subjects performed by Yamakoshi et al, ${ }^{24}$ in which indirect systolic and mean blood pressure of the digital artery were positively correlated with direct brachial arterial pressure. PPG blood measurements are feasible not only for fingers but also for arms, and systolic blood pressure in the brachial artery obtained using PPG corresponds to that obtained through invasive blood measurements in the same region. ${ }^{37}$ According to the results for $\mathrm{P}_{\mathrm{m}}$ in the six groups of subjects, the $\mathrm{P}_{\mathrm{m}}$ tended to increase with age, ${ }^{38-40}$ especially in women. Additionally, sex also influenced the different $\mathrm{P}_{\mathrm{m}}$ values in the 20- to 25-year-olds and the subjects over 50 years old. In the meantime, the higher $\Delta \mathrm{P}$ of digital artery compared with that of brachial artery was due to a wave reflection at the peripheral site. ${ }^{36}$ This pulse-pressure amplification resulted in equality of the $\Delta \mathrm{P}$ in the digital artery among the groups of subjects.

When the arterial elasticity of these six groups of subjects was analyzed and expressed as $\Delta \mathrm{V} / \Delta \mathrm{V}_{0}$ index, we found that age impacted the $\mathrm{P}_{\text {tr }}-\Delta \mathrm{V} / \Delta \mathrm{V}_{0}$ relationships and $\Delta \mathrm{V} / \Delta \mathrm{V}_{0}$ values at a $\mathrm{P}_{\text {tr }}$ of $30 \mathrm{mmHg}$ in the subjects who were older than 50 years. The $\Delta \mathrm{V} / \Delta \mathrm{V}_{0}$ values in subjects over 50 years old were distinctly higher than those in younger subjects when the $\mathrm{P}_{\text {tr }}$ was higher than $20 \mathrm{mmHg}$. The larger $\Delta \mathrm{V} / \Delta \mathrm{V}_{0}$ values at a certain $\mathrm{P}_{\text {tr }}$ level indicated that the arterial blood vessels of subjects over 50 years old had lower expansibility than those of younger subjects because of the loss of arterial elasticity in subjects over 50 years old. Moreover, the correlation between the $\Delta \mathrm{V} / \Delta \mathrm{V}_{0}$ value at a $\mathrm{P}_{\text {tr }}$ of $30 \mathrm{mmHg}$ and age also confirmed a reduction in arterial elasticity with age. The $\Delta \mathrm{V} / \Delta \mathrm{V}_{0}$ index was therefore capable of detecting changes in arterial elasticity with advancing age, similar to other arterial stiffness markers. ${ }^{9-11,29,31,32}$

However, when we considered arterial elasticity of subjects within the same age range, the $\mathrm{P}_{\text {tr }}-\Delta \mathrm{V} / \Delta \mathrm{V}_{0}$ relationships and the $\Delta \mathrm{V} / \Delta \mathrm{V}_{0}$ values at a $\mathrm{P}_{\text {tr }}$ of $30 \mathrm{mmHg}$ were not different between the sexes, while the men had different $\mathrm{P}_{\mathrm{m}}$ from the women within some age ranges, such as the 20- to 25-yearolds and subjects over 50 years old. These findings implied that the differences in the $\mathrm{P}_{\mathrm{m}}$ did not affect the $\mathrm{P}_{\mathrm{tr}}-\Delta \mathrm{V} / \Delta \mathrm{V}_{0}$ relationship or the $\Delta \mathrm{V} / \Delta \mathrm{V}_{0}$ value at certain $\mathrm{P}_{\text {tr }}$ values. In contrast, we found differences in the $\mathrm{P}_{\text {tr }}-\Delta \mathrm{V} / \Delta \mathrm{V}_{0}$ relationships and $\Delta \mathrm{V} / \Delta \mathrm{V}_{0}$ values among subjects who had the same $\mathrm{P}_{\mathrm{m}}$. For instance, although no difference in the $\mathrm{P}_{\mathrm{m}}$ was observed among each group of men, those who were over 50 years of age had larger $\Delta \mathrm{V} / \Delta \mathrm{V}_{0}$ values than the other two groups of men. 
Similar results were also seen when the 32- to 45 -year-old men and the women over 50 years old with the same $\mathrm{P}_{\mathrm{m}}$ were compared, with the $\Delta \mathrm{V} / \Delta \mathrm{V}_{0}$ values of the women who were over 50 years of age being higher than those of the other group. According to these results, we therefore deduced that using the $\mathrm{P}_{\text {tr }}-\Delta \mathrm{V} / \Delta \mathrm{V}_{0}$ relationship and the $\Delta \mathrm{V} / \Delta \mathrm{V}_{0}$ value at a certain $P_{\text {tr }}$ could be used to indicate the change or the difference in arterial elasticity without the influences of sex and different $\mathrm{P}_{\mathrm{m}}$ levels. On the other hand, many arterial stiffness parameters vary with the $\mathrm{P}_{\mathrm{m}}$ of the subjects. Both the carotid-femoral PWV and the brachial-ankle PWV increase with the $\mathrm{P}_{\mathrm{m}}$ of subjects, similar to the $\mathrm{d} / \mathrm{a}$ and e/a ratios of the second derivative of the digital pulse volume and the index of arterial stiffness, whereas the arterial compliance and ankle-brachial index are negatively correlated with the $\mathrm{P}_{\mathrm{m}}{ }^{10,19,41}$ Thus, the $\mathrm{P}_{\mathrm{m}}$ of an individual person is needed when the arterial stiffness of that person is evaluated using these parameters. In contrast, the $\mathrm{P}_{\mathrm{m}}$ is not necessary when the $\Delta V / \Delta V_{0}$ at a certain $P_{t r}$ from the AC signal of PPG is used.

Although the effect of the $\mathrm{P}_{\mathrm{m}}$ is not found in an evaluation based on the DC signal of the PPG, ${ }^{26,27}$ the effect of the tissues around the arterial system on the intensity of the DC component may reduce the accuracy of this technique. The existence of this effect was obviously seen when the $\mathrm{P}_{c}$ was greater than the $\mathrm{P}_{\text {sys }}$, as there must be no flow in the arterial system because of the complete collapse of the artery as a result of the $\mathrm{P}_{\mathrm{c}}$. This situation should result in a constant intensity of the DC component during the primary stage of occlusion, rather than a slow reduction in the recorded DC signal (Figure 2). Meanwhile, using the AC component of the PPG enables the influence of other tissues to be eliminated, and therefore truly reflects the changes in the arterial system, similar to the basic method of pulse oxymetry. ${ }^{42}$ Although $\Delta \mathrm{P}$ amplification might also affect evaluations using the $\Delta \mathrm{V} / \Delta \mathrm{V}_{0}$ of subjects with different arterial elasticities, we assigned the $\Delta \mathrm{P}$ to be a constant factor because of the equality of the $\Delta \mathrm{P}$ in the digital artery among the groups of subjects. The $\Delta \mathrm{P}$ consequently had no influence on the current investigations.

According to the results of the effect of the cold-stress stimulation on blood pressure, the cold-stress stimulation predominantly affected the $\mathrm{P}_{\mathrm{m}}$ by increasing it. The cold exposure induces a rise in skin sympathetic nerve activity, ${ }^{43}$ reduction of endothelial nitric oxide synthase activity, and higher affinity for noradrenaline on the plasma membrane. ${ }^{36}$ These neurogenic and vascular responses lead to a vasoconstriction observed by a decrease in vascular conductance, ${ }^{44}$ an increase in the $\mathrm{P}_{\mathrm{m}},{ }^{20,21,45}$ and reduction of cutaneous perfusion. ${ }^{46}$ Furthermore, the higher $\mathrm{P}_{\mathrm{m}}$ may be affected by the increase in myocardial oxygen demand, raising the oxygen uptake during body cooling. ${ }^{47}$ In the meantime, no significant influence of the cold-stress stimulation on the $\Delta \mathrm{P}$ was observed. In this experiment, the cold-stress stimulation mainly induced vasoconstriction, raising vascular resistance without changes in heart rate. ${ }^{21,47}$ When cardiac output remains constant during cold exposure, ${ }^{48}$ the unchanged heart rate maintains the constant level of the stroke volume. Consequently, both the $\mathrm{P}_{\text {sys }}$ and $\mathrm{P}_{\text {dia }}$ increased with the unaltered $\Delta \mathrm{P}$. Additionally, the large changes in the $\Delta \mathrm{P}$ due to the cold exposure were found for central blood pressure rather than peripheral blood pressure. ${ }^{45,47}$

Regarding the effect of cold-stress stimulation on the $\mathrm{P}_{\mathrm{tr}}-\Delta \mathrm{V} / \Delta \mathrm{V}_{0}$ relationship, there were no significant differences in $\mathrm{P}_{\mathrm{tr}}-\Delta \mathrm{V} / \Delta \mathrm{V}_{0}$ relationships among the three conditions, while cold-stress stimulation manifestly affected the $\mathrm{P}_{\mathrm{m}}$. These results also confirmed that the $\mathrm{P}_{\text {tr }}-\Delta \mathrm{V} / \Delta \mathrm{V}_{0}$ relationship was independent of the $\mathrm{P}_{\mathrm{m}}$. Although the cold exposure induced the reduction of amplitudes of the PPG AC signal, ${ }^{46}$ this stimulation did not influence the arterial elasticity analysis using the $\Delta \mathrm{V} / \Delta \mathrm{V}_{0}$ index. On the contrary, some arterial stiffness parameters are influenced by vasoconstriction and vasodilation, such as the volume elastic modulus and the AIx..$^{20,21,26,47,49}$

\section{Limitations of the study}

We did not evaluate the orientation and oxygenation levels of red blood cells that associate with changes in transmitted or reflected light intensity. These factors have caused the unreliable PPG measurement. ${ }^{22}$

The influences of some basic factors, ie, the occluding cuff size of PPG, age, sex, and cold-stress stimulation, on the arterial elasticity analysis using amplitude variations in the PPG pulse wave were evaluated in the small number of healthy subjects. The small number of subjects may be insufficient for confirmation of the aforementioned technique in the current clinical applications. This study is only the primary investigation of the development of the arterial elasticity analysis using PPG amplitude variation. Therefore, investigations of this technique under the influence of other factors, including pathophysiological conditions, in greater numbers of subjects are intended for future work. However, the present study can provide useful basic information for future analyses.

As for the results of the cold-stress stimulation, the $\mathrm{P}_{\mathrm{tr}}-\Delta \mathrm{V} / \Delta \mathrm{V}_{0}$ relationship tended to depend on the $\Delta \mathrm{P}$ (which was constant for all the three conditions). Cold exposure is found to stimulate rising $\mathrm{PWV}$ and rising $\Delta \mathrm{P}$ in old adults. ${ }^{20}$ 
Because we investigated the effect of cold-stress stimulation on the $\mathrm{P}_{\mathrm{tr}}-\Delta \mathrm{V} / \Delta \mathrm{V}_{0}$ relationship in young adults, we could not certainly deduce that cold-stress stimulation did not influence the $\Delta \mathrm{P}$ or the $\mathrm{P}_{\mathrm{tr}}-\Delta \mathrm{V} / \Delta \mathrm{V}_{0}$ relationship for all ages. The effect of the $\Delta \mathrm{P}$ is therefore necessary for future studies to prove progressively the capability of using this method for arterial elasticity analysis. Although the effect of the $\Delta \mathrm{P}$ on the $\mathrm{P}_{\text {tr }}-\Delta \mathrm{V} / \Delta \mathrm{V}_{0}$ relationship was beyond the scope of this study, the aforementioned results indicated the independence of the $\mathrm{P}_{\mathrm{tr}}-\Delta \mathrm{V} / \Delta \mathrm{V}_{0}$ relationship from the vascular stimulation, which predominantly influenced the $\mathrm{P}_{\mathrm{m}}$.

\section{Conclusion}

We proposed a simple methodology for analyzing arterial elasticity in the human finger by examining variations in the AC component of the PPG signal. We defined the $\Delta \mathrm{V} / \Delta \mathrm{V}_{0}$ as the vascular elasticity index and expressed it in the form of the $\mathrm{P}_{\mathrm{tr}}-\Delta \mathrm{V} / \Delta \mathrm{V}_{0}$ relationship and the $\Delta \mathrm{V} / \Delta \mathrm{V}_{0}$ value at a certain $\mathrm{P}_{\text {tr }}$. This method was primarily applied to evaluate arterial elasticity under the effect of occluding cuff size for obtaining the suitable cuff size. We also evaluated the effects of basic factors (age, sex, and cold-stress stimulation) on arterial elasticity using this method. As the results of this study showed, an excessively small cuff seemed to be unsuitable for estimating the arterial elasticity using the $\Delta \mathrm{V} / \Delta \mathrm{V}_{0}$ from the AC signal of $\mathrm{PPG}$, especially in large fingers. Meanwhile, the $\mathrm{P}_{\mathrm{tr}}-\Delta \mathrm{V} / \Delta \mathrm{V}_{0}$ relationship and the $\Delta \mathrm{V} / \Delta \mathrm{V}_{0}$ values changed with advancing age, whereas sex and differences in the $\mathrm{P}_{\mathrm{m}}$ had no impact on them. Although the impact of cold-stress stimulation on the $\mathrm{P}_{\mathrm{tr}}-\Delta \mathrm{V} / \Delta \mathrm{V}_{0}$ relationship was not certainly deduced for all ages, this impact demonstrated the independence of the $\mathrm{P}_{\operatorname{tr}}-\Delta \mathrm{V} / \Delta \mathrm{V}_{0}$ relationship from the vascular stimulation, which directly affected the $\mathrm{P}_{\mathrm{m}}$. According to the results of this study, $\Delta \mathrm{V} / \Delta \mathrm{V}_{0}$ assessments using amplitude variations of the AC component of PPG could possibly be used as an alternative technique for analyzing arterial elasticity, which can be applied together with other techniques to increase the efficiency of medical diagnoses.

\section{Acknowledgments}

This study was supported in part by a grant-in-aid for scientific research and grant-in-aid for challenging exploratory research from the Ministry of Education, Culture, Sports, Science and Technology, Japan.

\section{Disclosure}

The authors report no conflicts of interest in this work.

\section{References}

1. Avolio AP, Chen SG, Wang RP, Zhang CL, Li MF, O'Rourke MF. Effects of aging on changing arterial compliance and left ventricular load in a northern Chinese urban community. Circulation. 1983;68(1):50-58.

2. Fonck E, Prod'hom G, Roy S, Augsburger L, Rüfenacht DA, Stergiopulos N. Effect of elastin degradation on carotid wall mechanics as assessed by a constituent-based biomechanical model. Am J Physiol Heart Circ Physiol. 2007;292(6):H2754-H2763.

3. Lee H, Oh B. Aging and arterial stiffness. Circ J. 2010;74(11): 2257-2262.

4. Sutton-Tyrrell K, Najjar SS, Boudreau RM, et al. Elevated aortic pulse wave velocity, a marker of arterial stiffness, predicts cardiovascular events in well-functioning older adults. Circulation. 2005;111(25):3384-3390.

5. Vlachopoulos C, Aznaouridis K, Stefanadis C. Prediction of cardiovascular events and all-cause mortality with arterial stiffness: a systematic review and meta-analysis. J Am Coll Cardiol. 2010;55(13): 1318-1327.

6. Franklin SS, Gustin W, Wong ND, et al. Hemodynamic patterns of age-related changes in blood pressure. The Framingham Heart Study. Circulation. 1997;96(1):308-315.

7. Franklin SS, Wilkinson IB, McEniery CM. Unusual hypertensive phenotypes: what is their significance? Hypertension. 2012;59(2): 173-178.

8. Fantin F, Mattocks A, Bulpitt CJ, Banya W, Rajkumar C. Is augmentation index a good measure of vascular stiffness in the elderly? Age Aging. 2007;36(1):43-48.

9. Kelly R, Hayward C, Avolio A, O’Rourke M. Noninvasive determination of age-related changes in the human arterial pulse. Circulation. 1989;80(6):1652-1659.

10. Millasseau SC, Kelly RP, Ritter JM, Chowienczyk PJ. Determination of age-related increases in large artery stiffness by digital pulse contour analysis. Clin Sci. 2002;103(4):371-377.

11. Mitchell GF, Parise H, Benjamin EJ, et al. Changes in arterial stiffness and wave reflection with advancing age in healthy men and women: the Framingham Heart Study. Hypertension. 2004;43(6): 1239-1245.

12. Hlimonenko I, Meigas K, Viigimaa M, Temitski K. Assessment of pulse wave velocity and augmentation index in different arteries in patients with severe coronary heart disease. Conf Proc IEEE Eng Med Biol Soc. 2007;2007:1703-1706.

13. Wilkinson IB, Prasad K, Hall IR, et al. Increased central pulse pressure and augmentation index in subjects with hypercholesterolemia. J Am Coll Cardiol. 2002;39(6):1005-1011.

14. Cruickshank K, Riste L, Anderson SG, Wright JS, Dunn G, Gosling RG. Aortic pulse-wave velocity and its relationship to mortality in diabetes and glucose intolerance: an integrated index of vascular function? Circulation. 2002;106(16):2085-2090.

15. Wilhelm B, Klein J, Friedrich C, et al. Increase arterial augmentation and augmentation index as surrogate parameters for arteriosclerosis in subjects with diabetes mellitus and nondiabetic subjects with cardiovascular disease. J Diabetes Sci Technol. 2007;1(2):260-263.

16. London GM, Blacher J, Pannier B, Guérin AP, Marchais SJ, Safar ME. Arterial wave reflections and survival in end-stage renal failure. Hypertension. 2001;38(3):434-438.

17. Miyatani M, Masani K, Oh PI, Miyachi M, Popovic MR, Craven BC. Pulse wave velocity for assessment of arterial stiffness among people with spinal cord injury: a pilot study. J Spinal Cord Med. 2009;32(1):72-78.

18. Callaghan FJ, Geddes LA, Babbs CF, Bourland JD. Relationship between pulse-wave velocity and arterial elasticity. Med Biol Eng Comput. 1986;24(3):248-254.

19. Li B, Gao H, Li X, Liu Y, Wang M. Correlation between brachial-ankle pulse wave velocity and arterial compliance and cardiovascular risk factors in elderly patients with arteriosclerosis. Hypertens Res. 2006; 29(5):309-314. 
20. Hess KL, Wilson TE, Sauder CL, Gao Z, Ray CA, Monahan KD. Aging affects the cardiovascular responses to cold stress in humans. J Appl Physiol. 2009;107(4):1076-1082.

21. Huang $\mathrm{C}$, Chang $\mathrm{H}, \mathrm{Kao} \mathrm{S}$, et al. Radial pressure pulse and heart rate variability in heat- and cold-stressed humans. Evid Based Complement Alternat Med. 2011;2011:751317.

22. Challoner AVJ. Photoelectric plethysmography for estimating cutaneous blood flow. In: Rolfe P, editor. Non-invasive Physiological Measurements. London: Academic Press; 1979:125-151.

23. Jeong I, Jun S, Um D, Oh J, Yoon H. Non-invasive estimation of systolic blood pressure and diastolic blood pressure using photoplethysmograph components. Yonsei Med J. 2010;51(3):345-353.

24. Yamakoshi K, Shimazu H, Shibata M, Kamiya A. New oscillometric method for indirect measurement of systolic and mean arterial pressure in the human finger. Part 2: correlation study. Med Biol Eng Comput. 1982;20(3):314-318

25. Allen J. Photoplethysmography and its application in clinical physiological measurement. Physiol Meas. 2007;28(3):R1-R39.

26. Kawarada A, Shimazu H, Yamakoshi K, Kamiya A. Noninvasive automatic measurement of arterial elasticity in human fingers and rabbit forelegs using photoelectric plethysmography. Med Biol Eng Comput. 1986;24(6):591-596

27. Ando J, Kawarada A, Shibata M, Yamakoshi K, Kamiya A. Pressurevolume relationships of finger arteries in healthy subjects and patients with coronary atherosclerosis measured non-invasively by photoelectric plethysmography. Jpn Circ J. 1991;55(6):567-575.

28. Gonzalez R, Manzo A, Delgado J, Padilla JM, Trenor B, Saiz J. A computer based photoplethysmographic vascular analyzer through derivatives. Comput Cardiol. 2008;35:177-180.

29. Hlimonenko I, Meigas K, Vahisalu R. Waveform analysis of peripheral pulse wave detected in the fingertip with photoplethysmograph. Meas Sci Rev. 2003;3(2):49-52.

30. Takazawa K, Tanaka N, Fujita M, et al. Assessment of vasoactive agents and vascular aging by the second derivative of photoplethysmogram waveform. Hypertension. 1998;32(2):365-370.

31. Jayasree VK, Sandhya TV, Radhakrishnan P. Non-invasive studies on age related parameters using a blood volume pulse sensor. Meas $\mathrm{Sci}$ Rev. 2008;8(2):82-86.

32. Huotari M, Yliaska N, Lantto V, Määttä K, Kostamovaara J. Aortic and arterial stiffness determination by photoplethysmographic technique. Procedia Chem. 2009;1(1):1243-1246.

33. Tanaka G, Yamakoshi K, Sawada Y, et al. A novel photoplethysmography technique to derive normalized arterial stiffness as a blood pressure independent measure in the finger vascular bed. Physiol Meas. 2011;32(11):1869-1883.

34. Norman GR, Streiner DL. Biostatistics: The Bare Essentials, 3rd ed. Hamilton (ON): BC Decker; 2008.
35. Jones RD, Kornberg JP, Roulson CJ, Visram AR, Irwin MG. The Finapres $2300 \mathrm{E}$ finger cuff. The influence of cuff application on the accuracy of blood pressure measurement. Anaesthesia. 1993;48(7): 611-615.

36. Levick JR. An Introduction to Cardiovascular Physiology, 5th ed. London: Hodder; 2010.

37. Laurent C, Jönsson B, Vegfors M, Lindberg LG. Non-invasive measurement of systolic blood pressure on the arm utilising photoplethysmography: development of the methodology. Med Biol Eng Comput. 2005;43(1):131-135.

38. Mungreiphy NK, Kapoor S, Sinha R. Association between BMI, blood pressure, and age: study among Tangkhul Naga tribal males of Northeast India. J Anthropol. 2011;2011:1-6.

39. Pearson JD, Morrell CH, Brant LJ, Landis PK, Fleg JL. Age-associated changes in blood pressure in a longitudinal study of healthy men and women. J Gerontol A Biol Sci Med Sci. 1997;52(3):M177-M183.

40. Rodriguez BL, Labarthe DR, Huang B, Lopez-Gomez J. Rise of blood pressure with age. New evidence of population differences. Hypertension. 1994;24(6):779-785.

41. Šimek J, Wichterle D, Melenovský V, Malík J, Svačina Š, Widimský J. Second derivative of the finger arterial pressure waveform: an insight into dynamics of the peripheral arterial pressure pulse. Physiol Res. 2005;54(5):505-513.

42. Jubran A. Pulse oximetry. Crit Care. 1999;3(2):R11-R17.

43. Sawasaki N, Iwase S, Mano T. Effect of skin sympathetic response to local or systemic cold exposure on thermoregulatory functions in humans. Auton Neurosci. 2001;87(2-3):274-281.

44. Wilson TE, Sauder CL, Kearney ML, et al. Skin-surface cooling elicits peripheral and visceral vasoconstriction in humans. J Appl Physiol. 2007;103(4):1257-1262.

45. Lafleche AB, Pannier BM, Laloux B, Safar ME. Arterial response during cold pressor test in borderline hypertension. Am J Physiol. 1998; 275(2 Pt 2):H409-H415.

46. Mateus J, Hargens AR. Photoplethysmography for non-invasive in vivo measurement of bone hemodynamics. Physiol Meas. 2012; 33(6): 1027-1042.

47. Edwards DG, Gauthier AL, Hayman MA, Lang JT, Kenefick RW. Acute effects of cold exposure on central aortic wave reflection. J Appl Physiol. 2006;100(4):1210-1214.

48. Mourot L, Bouhaddi M, Regnard J. Effects of the cold pressor test on cardiac autonomic control in normal subjects. Physiol Res 2009;58(1):83-91.

49. Munir S, Jiang B, Guilcher A, et al. Exercise reduces arterial pressure augmentation through vasodilation of muscular arteries in humans. Am J Physiol Heart Circ Physiol. 2008;294(4):H1645-H1650.
Vascular Health and Risk Management

\section{Publish your work in this journal}

Vascular Health and Risk Management is an international, peerreviewed journal of therapeutics and risk management, focusing on concise rapid reporting of clinical studies on the processes involved in the maintenance of vascular health; the monitoring, prevention and treatment of vascular disease and its sequelae; and the involvement of

\section{Dovepress}

metabolic disorders, particularly diabetes. This journal is indexed on PubMed Central and MedLine. The manuscript management system is completely online and includes a very quick and fair peer-review system, which is all easy to use. Visit http://www.dovepress.com/ testimonials.php to read real quotes from published authors. 